\section{BMJ Open Respiratory Research}

\title{
Patterns and management of chronic obstructive pulmonary disease in urban and rural China: a community-based survey of 25000 adults across 10 regions
}

Om P Kurmi, ${ }^{1}$ Kourtney J Davis, ${ }^{2}$ Kin Bong Hubert Lam, ${ }^{1}$ Yu Guo, ${ }^{3}$ Julien Vaucher, ${ }^{1}$ Derrick Bennett, ${ }^{1}$ Jenny Wang, ${ }^{1}$ Zheng Bian, ${ }^{3}$ Huaidong Du, ${ }^{1}$ Liming Li, ${ }^{4}$ Robert Clarke, ${ }^{1}$ Zhengming Chen, ${ }^{1}$ for the China Kadoorie Biobank Collaborative Group

To cite: Kurmi OP, Davis KJ, Hubert Lam KB, et al. Patterns and management of chronic obstructive pulmonary disease in urban and rural China: a community-based survey of 25000 adults across 10 regions. BMJ Open Resp Res 2018;5:e000267. doi:10.1136/ bmjresp-2017-000267

- Additional material is published online only. To view, please visit the journal online (http://dx.doi.org/10. 1136/bmjresp-2017-000267).

Received 28 November 2017 Revised 16 January 2018 Accepted 28 January 2018
Check for updates

${ }^{1}$ Clinical Trial Service Unit and Epidemiological Studies Unit (CTSU), Nuffield Department of Population Health, University of Oxford, Oxford, UK

${ }^{2}$ Real World Evidence and Epidemiology, GlaxoSmithKline, Collegeville, Pennsylvania, USA

${ }^{3}$ National Co-ordinating Centre for China Kadoorie Biobank, Chinese Academy of Medical Sciences, Beijing, China ${ }^{4}$ Department of Epidemiology, Peking University Health Science Center, School of Public Health, Beijing, China

Correspondence to Dr Om P Kurmi; omkurmi@googlemail.com

\section{ABSTRACT}

Introduction Chronic obstructive pulmonary disease (COPD) is the third leading cause of death worldwide, with COPD deaths in China accounting for one-third of all such deaths. However, there is limited available evidence on the management of COPD in China.

Methods A random sample of 25011 participants in the China Kadoorie Biobank, aged 38-87 years, from 10 regions in China was surveyed in 2013-2014. Data were collected using interviewer-administered questionnaires on the diagnosis ('doctor-diagnosed' or 'symptoms-based') and management of COPD (including use of medication and other healthcare resources), awareness of diagnosis and severity of symptoms in COPD cases.

Results Overall, $6.3 \%$ of the study population were identified as COPD cases (doctor-diagnosed cases: $4.8 \%$ and symptom-based cases: $2.4 \%$ ). The proportion having COPD was higher in men than in women $(7.9 \%$ vs $5.3 \%)$ and varied by about threefold $(3.7 \%-10.0 \%)$ across the 10 regions. Among those with COPD, 54\% sought medical advice during the last 12 months, but $<10 \%$ reported having received treatment for COPD. The rates of hospitalisation for COPD, use of oxygen therapy at home and influenza or pneumococcal vaccinations in the previous year were $15 \%, 3 \%$ and $4 \%$, respectively. Of those with COPD, half had moderate or severe respiratory symptoms, and over $80 \%$ had limited understanding of their disease and need for treatment.

Conclusion Despite a high prevalence of COPD in China and its substantial impact on activities of daily living, knowledge about COPD and its management were limited.

\section{INTRODUCTION}

Although there has been a gradual decline in age-standardised mortality rates worldwide over the last two decades, chronic obstructive pulmonary disease (COPD) is still a leading cause of death, ${ }^{1}$ accounting for about 3 million deaths in $2010 .^{1}$ About $70 \%$ of all COPD deaths worldwide now occur in South and East Asia, ${ }^{2}$ where the burden of COPD is projected to increase over the next few decades due to a high prevalence of

\section{Key messages}

Overall, about $6 \%$ of the study population had chronic obstructive pulmonary disease (COPD), but the prevalence varied almost threefold across the 10 study regions in China.

> Among COPD cases identified in China, one-half sought medical advice in the previous year and $<1$ in 10 reported having any treatment for COPD.

$>$ Overall, four-fifths of COPD cases had limited understanding of their diagnosis or of the need for specific treatment for COPD.

smoking and rapidly ageing populations. ${ }^{34}$ China alone contributed to about one-third (0.9 million/year) of all deaths from COPD worldwide. Within China, the prevalence of COPD varies substantially by region ${ }^{56}$ and death rates attributed to COPD are twofold greater in South-West $t^{5}$ compared with NorthEast regions for reasons that are not fully understood. $^{3}$

Despite the high burden of COPD, there is limited available evidence on diagnosis and management of COPD in China. Using data on 25000 adults from a nationwide survey in 2013-2014 across 10 regions of China, as part of the China Kadoorie Biobank (CKB), we examined the diagnosis of COPD and the knowledge, management and severity among cases with COPD, overall and by age, sex and region.

\section{METHODS}

\section{Study population}

The CKB study is a prospective study of over 0.5 million adults, aged $30-79$ years at baseline, who were recruited from 10 geographically diverse regions across China between 


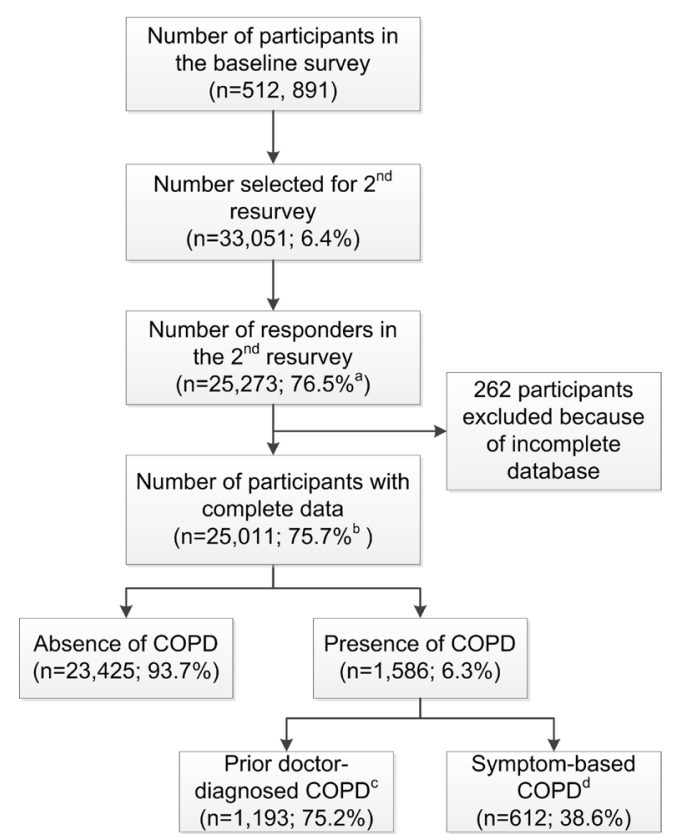

Figure 1 Flow diagram of participants included in the survey. ${ }^{a}$ Response rate. ${ }^{b}$ Actual response rate (participants included in the analysis and had completed all sections that comprised questionnaire, physical measurements and tests during the second resurvey). ${ }^{\circ}$ Chronic obstructive pulmonary disease (COPD) defined by history of doctor diagnosis of COPD=COPD and/or chronic bronchitis and/ or emphysema. dSymptom-based COPD are those with self-reported chronic cough, that is, productive cough for at least 3 months for 2 consecutive years.

2004 and $2008 .^{78}$ A random sample of about $6 \%$ surviving participants underwent periodic resurveys every 4-5 years including repeat interviews, physical measurements and collection of biological samples. The present report is based on the 25011 individuals who participated in the second resurvey during 2013-2014, and had an overall response rate of $76 \%$ (figure 1). Detailed information was collected using interviewer-administered laptopbased questionnaires on personal and sociodemographic characteristics, lifestyle (including questions on diet, smoking, alcohol and physical activity) and medical history (including questions on specific conditions, such as COPD). Each individual provided a written consent to participate in this study.

\section{Definition of COPD cases}

In this report, COPD cases (see online supplementary figure 1) were defined using two different criteria:

i. Participants who answered 'yes' to the question "Have you had chronic productive cough for 3 months or more during at least two consecutive years" were classified as having symptom-based $C O P D^{9}$;

ii. Participants who answered 'yes' to the question "Has a doctor ever told you that you had COPD, chronic bronchitis or emphysema" were classified as having doctor-diagnosed COPD.

\section{Assessment of severity and management of COPD}

All participants with COPD were requested to complete additional questions on: (i) COPD-related health status using the COPD Assessment Test (CAT) ${ }^{10}$ and (ii) knowledge, severity and management of COPD, including visits to health professionals, regular use of medication within the previous 7 days, management of exacerbations, influenza and pneumococcal vaccinations and use of oxygen therapy in the last 12 months (see online supplementary appendix 1). ${ }^{11}$

Participants with doctor-diagnosed COPD were also asked to provide: (i) age at first diagnosis; (ii) use of treatment at the time of the resurvey; (iii) any hospitalisation for an acute exacerbation of COPD and (iv) date of last hospitalisation for COPD.

\section{Lung function measurement}

All participants except those with contraindications ${ }^{12}$ had lung function assessed using a personal computer-based spirometer (Pneumotrac 6800, Vitalograph, Buckingham, UK) by trained technicians. After conducting some practice exhalations, the results of at least two reproducible measurements (difference of at least two forced expiratory volume in $1 \mathrm{~s}$ and forced vital capacity $<150 \mathrm{~mL}$ ) were recorded. The spirograms of those with symptom-based or doctor-diagnosed COPD were reviewed independently for quality by two authors (OK and KBHL) following the European Respiratory Society/American Thoracic Society (ERS/ATS) guidelines. ${ }^{13}$ Out of 1586 doctor-diagnosed/symptom-based COPD participants, $55(3.5 \%)$ did not have lung function tests conducted due to contraindications, $1282(83.7 \%)$ of those with lung function tests had acceptable spirometry and $600(37.8 \%)$ had COPD confirmed by spirometry (defined by lower limit of normal criteria) based on prebronchodilator measured lung function. ${ }^{14}$

\section{Statistical analysis}

Linear and logistic regression analyses were used for continuous and binary outcomes, respectively, after stratification for age (five groups), sex and region (10 groups). Likewise, adjusted means (SD) or proportions with their associated 95\% CI, respectively, were also stratified by age, sex and region at the time of second resurvey. Similar analyses were carried out to estimate age (five groups) and sex-adjusted means (and their SD) or proportions, respectively, for patient-reported symptoms and use of medication by region. All the above analyses were repeated after stratification for the three classification schemes for COPD: symptom-based, doctor-diagnosed and those spirometry-confirmed.

\section{RESULTS}

\section{Characteristics of participants with COPD}

Overall, $6.3 \%$ of participants had COPD, with two-thirds of the cases $(4.8 \%)$ being doctor-diagnosed and one-third 

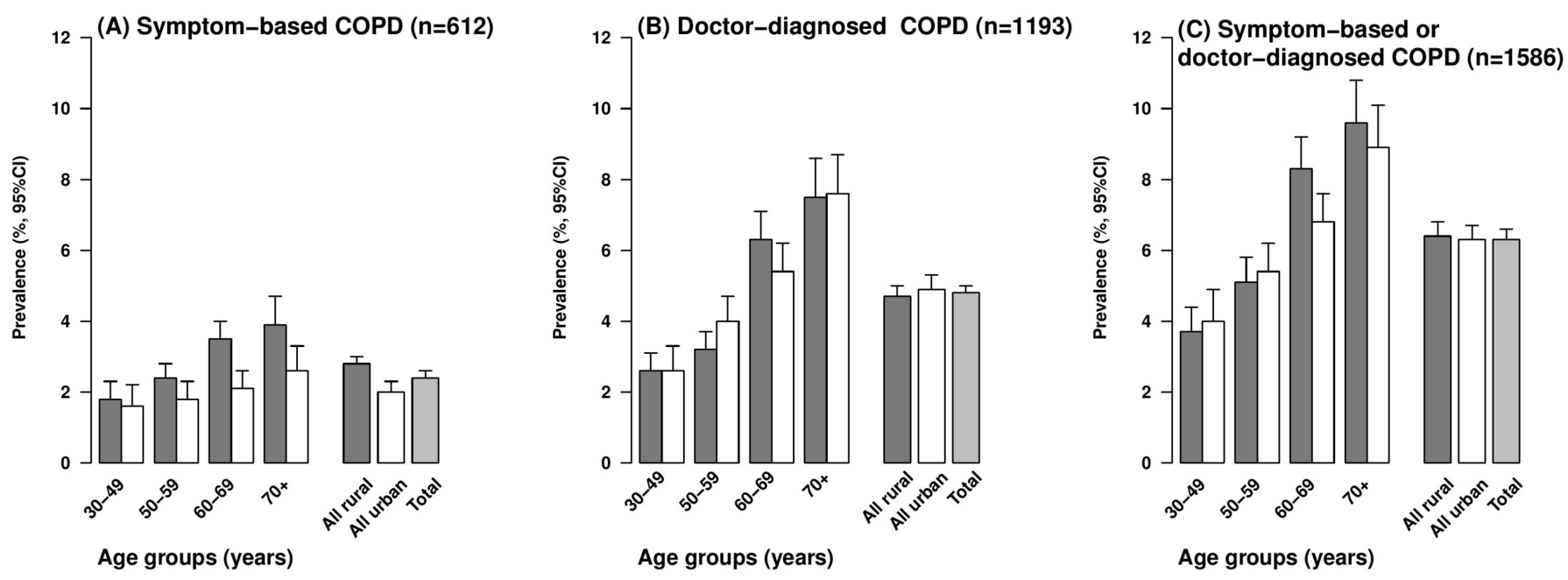

Figure 2 Prevalence of chronic obstructive pulmonary disease (COPD) defined by different criteria by age, and place of residence. The dark grey bar represents 'rural' participants and white bar represents 'urban' participants.

(2.4\%) being symptom-based (figure 1). The proportion having COPD increased with age (from $3.8 \%$ at age $30-49$ years to $9.3 \%$ at age $\geq 70$ years) and was $50 \%$ greater in men than in women $(7.9 \%$ vs $5.3 \%)$ (table 1 and figure 2). Men reported a higher proportion of symptom-based COPD than women $(58 \%$ vs $42 \%)$. The gender differences in COPD reflect the much higher prevalence of smoking in men than in women $(73 \%$ vs $4 \%)$, but the combined ex-smokers had the highest prevalence of COPD (12.8\%) (table 1). Overall, the mean age of ex-smokers (63.8 years) was about 5 years older than that for either current smokers (58.4 years) or never regular smokers (58.7 years). Although the overall proportion having COPD was similar in rural $(6.5 \%)$ and urban $(6.2 \%)$ areas, it varied by about threefold across the geographically defined 10 regions (from $3.7 \%$ in Haikou to $10.0 \%$ in Sichuan; figure 3). Although, the proportion of participants with COPD was slightly lower in never regular smokers compared with the overall participants, this proportion in never-smokers varied threefold between regions (2.5\% in Haikou vs $8.5 \%$ in Sichuan).

Doctor-diagnosed COPD was more common than symptom-based COPD in older participants ( $\geq 60$ years) (figure 2). Irrespective of the case definition, participants reporting COPD tended to have a lower income, be underweight (BMI $<18.5 \mathrm{~kg} / \mathrm{m}^{2}$ ) and have poor self-assessed health status (table 1). Concomitant illnesses including asthma, ischaemic heart disease, rheumatoid arthritis and tuberculosis were usually twofold more frequent among those with doctor-diagnosed COPD compared with those with symptom-based COPD (see online supplementary table 1).

\section{Management of COPD}

Just over half of those with COPD visited a health professional in the previous 12 months (prior to the survey), slightly higher among those with doctor-diagnosed COPD compared with symptom-based COPD (63\% vs
$43 \%)$; the majority of which $(34 \%)$ involved consultation with a general physician (table 2). Compared with their urban counterparts, rural residents were less likely to seek medical advice (50\% vs $61 \%$ ) despite a higher proportion of them reporting more severe conditions (21\% vs $15 \%$ ) (see online supplementary table 2 ).

Use of any medication in the last 7 days to alleviate symptoms and to reduce the frequency and severity of exacerbations was reported by $9 \%$ of the COPD cases, with short-acting bronchodilators reported as the most frequently used medication. Use of oxygen therapy at home was low (2.8\%), as were guideline recommended influenza or pneumococcal vaccinations $(3.7 \%)$ (table 2). Doctor-diagnosed COPD cases were more likely to have used prescribed medications in the last 7 days than symptom-based COPD cases $(10.2 \%$ vs $9.2 \%)$. The use of medication was greater in older age groups in both rural and urban areas (figure 4). Interestingly, Sichuan, the region with the highest prevalence of COPD, had the lowest reported use of medication $(10.3 \%)$ in the last 12 months (table 3). Overall, $15 \%$ of cases were ever hospitalised for their pulmonary condition during the last 12 months and about one-third reported having received antibiotics, or oral or injectable corticosteroids for an acute COPD exacerbation. Around $25 \%$ of those who were recently prescribed medication reported having at least one COPD exacerbation in the last 12 months (table 2).

\section{Severity of COPD, functional status and awareness of diagnosis}

Overall, one-fifth of the participants with COPD reported having either severe or very severe respiratory symptoms, with a slightly higher proportion in never-smokers (20\%) and rural dwellers (21\%) compared with ever-smokers $(18 \%)$ and urban dwellers (15\%), respectively (table 2, online supplementary tables 2 and 3). A moderate or severe CAT score $(\geq 10)$ was reported by $44 \%$ of COPD 
Table 1 Prevalence of symptom-based COPD, doctor-diagnosed COPD or either, by second resurvey characteristics

\begin{tabular}{|c|c|c|c|c|}
\hline Characteristics & Study population & $\begin{array}{l}\text { Symptom-based } \\
\text { COPD* } \\
\%(95 \% \mathrm{Cl})\end{array}$ & $\begin{array}{l}\text { Doctor-diagnosed } \\
\text { COPD† } \\
\%(95 \% \mathrm{Cl})\end{array}$ & $\begin{array}{l}\text { Symptom-based or } \\
\text { doctor-diagnosed } \\
\text { COPD } \\
\%(95 \% \mathrm{Cl}) \\
\end{array}$ \\
\hline All participants (\%) & 25011 & $612(2.4)$ & $1193(4.8)$ & $1586(6.4)$ \\
\hline \multicolumn{5}{|l|}{ Age at resurvey (years) } \\
\hline $30-49$ & 5500 & 1.7 (1.4 to 2.1$)$ & 2.6 (2.2 to 3.0$)$ & 3.8 (3.3 to 4.4$)$ \\
\hline $50-59$ & 7722 & 2.1 (1.8 to 2.5 ) & 3.6 (3.2 to 4.0$)$ & 5.2 (4.7 to 5.7$)$ \\
\hline $60-69$ & 7449 & 2.9 (2.5 to 3.3 ) & 6.0 (5.4 to 6.5 ) & 7.7 (7.0 to 8.3$)$ \\
\hline $70+$ & 4340 & 3.3 (2.8 to 3.9 ) & 7.5 (6.7 to 8.3$)$ & 9.3 (8.4 to 10.2$)$ \\
\hline \multicolumn{5}{|l|}{ Sex } \\
\hline Men & 9580 & 3.7 (3.3 to 4.0$)$ & 5.4 (5.0 to 5.9$)$ & 7.9 (7.4 to 8.5$)$ \\
\hline Women & 15431 & 1.7 (1.5 to 1.9$)$ & 4.3 (4.0 to 4.6 ) & 5.3 (5.0 to 5.7 ) \\
\hline \multicolumn{5}{|l|}{ Area } \\
\hline Rural & 14235 & 2.8 (2.5 to 3.1$)$ & 4.7 (4.4 to 5.1$)$ & 6.5 (6.1 to 6.9$)$ \\
\hline Urban & 10776 & 2.0 (1.7 to 2.3 ) & 4.8 (4.4 to 5.2 ) & 6.2 (5.7 to 6.6 ) \\
\hline \multicolumn{5}{|l|}{ Education } \\
\hline None & 5068 & 2.3 (1.2 to 3.4$)$ & 4.0 (3.1 to 4.9$)$ & 5.7 (4.2 to 7.1$)$ \\
\hline Primary & 8032 & 2.2 (1.9 to 2.5 ) & 4.5 (4.0 to 5.0 ) & 5.9 (5.3 to 6.4$)$ \\
\hline Secondary or tertiary & 11911 & 2.5 (2.1 to 3.0$)$ & 4.7 (4.1 to 5.3$)$ & 6.6 (5.9 to 7.3 ) \\
\hline \multicolumn{5}{|l|}{ Household income (¥) } \\
\hline$<10000$ & 2175 & 2.9 (2.2 to 3.5$)$ & 5.5 (4.2 to 6.7$)$ & 7.3 (6.0 to 8.7$)$ \\
\hline 10000-19999 & 3079 & 3.1 (2.1 to 4.0$)$ & 4.8 (3.6 to 6.0 ) & 6.7 (5.3 to 8.0 ) \\
\hline$\geq 20000$ & 19757 & 2.4 (2.1 to 2.6 ) & 4.8 (4.5 to 5.1$)$ & 6.3 (6.0 to 6.7$)$ \\
\hline \multicolumn{5}{|l|}{ Smoking status } \\
\hline Never & 18274 & 1.8 (1.6 to 2.0 ) & 4.6 (4.2 to 4.9$)$ & 5.7 (5.3 to 6.1$)$ \\
\hline Ex-regular & 1611 & 3.6 (1.9 to 5.4 ) & 11.1 (9.3 to 12.9$)$ & 12.8 (10.6 to 15.0$)$ \\
\hline Current regular & 5126 & 2.9 (2.4 to 3.4$)$ & 3.7 (2.6 to 4.8$)$ & 5.9 (4.8 to 7.0$)$ \\
\hline \multicolumn{5}{|l|}{ Body mass index $\left(\mathrm{kg} / \mathrm{m}^{2}\right)$} \\
\hline$<18.5$ & 950 & 4.0 (2.7 to 5.2$)$ & 8.9 (7.0 to 10.8$)$ & 10.7 (8.6 to 12.7$)$ \\
\hline $18.5-25.0$ & 14289 & 2.3 (2.0 to 2.5 ) & 4.5 (4.1 to 4.8 ) & 5.9 (5.5 to 6.3 ) \\
\hline$\geq 25.0$ & 9772 & 2.5 (2.2 to 2.9 ) & 4.9 (4.4 to 5.4$)$ & 6.7 (6.2 to 7.2 ) \\
\hline \multicolumn{5}{|c|}{ Physical activities (MET-hour/day) } \\
\hline$<10$ & 14129 & $2.7(2.3$ to 3.1$)$ & 4.9 (4.5 to 5.3$)$ & $6.6(6.1$ to 7.2$)$ \\
\hline $10-14$ & 1722 & 2.3 (1.6 to 3.1$)$ & 4.3 (3.2 to 5.3 ) & 5.6 (4.4 to 6.8$)$ \\
\hline$\geq 14$ & 9160 & 2.3 (1.8 to 2.7$)$ & 4.8 (4.1 to 5.6$)$ & $6.3(5.5$ to 7.1$)$ \\
\hline \multicolumn{5}{|c|}{ Self-assessed health status } \\
\hline Good/excellent & 10943 & 1.5 (1.3 to 1.7$)$ & 2.7 (2.4 to 3.0$)$ & 3.8 (3.5 to 4.2$)$ \\
\hline Fair & 10851 & 2.4 (2.1 to 2.7$)$ & 4.9 (4.5 to 5.4$)$ & $6.7(6.2$ to 7.1$)$ \\
\hline Poor & 3217 & 5.4 (4.6 to 6.2$)$ & $10.0(8.9$ to 11.1$)$ & $12.9(11.7$ to 14.1$)$ \\
\hline
\end{tabular}

*Symptom-based COPD are those with self-reported chronic cough, that is, productive cough for at least 3 months for two consecutive years.

†COPD defined by history of doctor diagnosis of COPD, where COPD=COPD and/or chronic bronchitis and/or emphysema.

$\ddagger$ Either * or †; standardised for region, age group and gender as appropriate.

COPD, chronic obstructive pulmonary disease; MET, metabolic equivalent of task. 


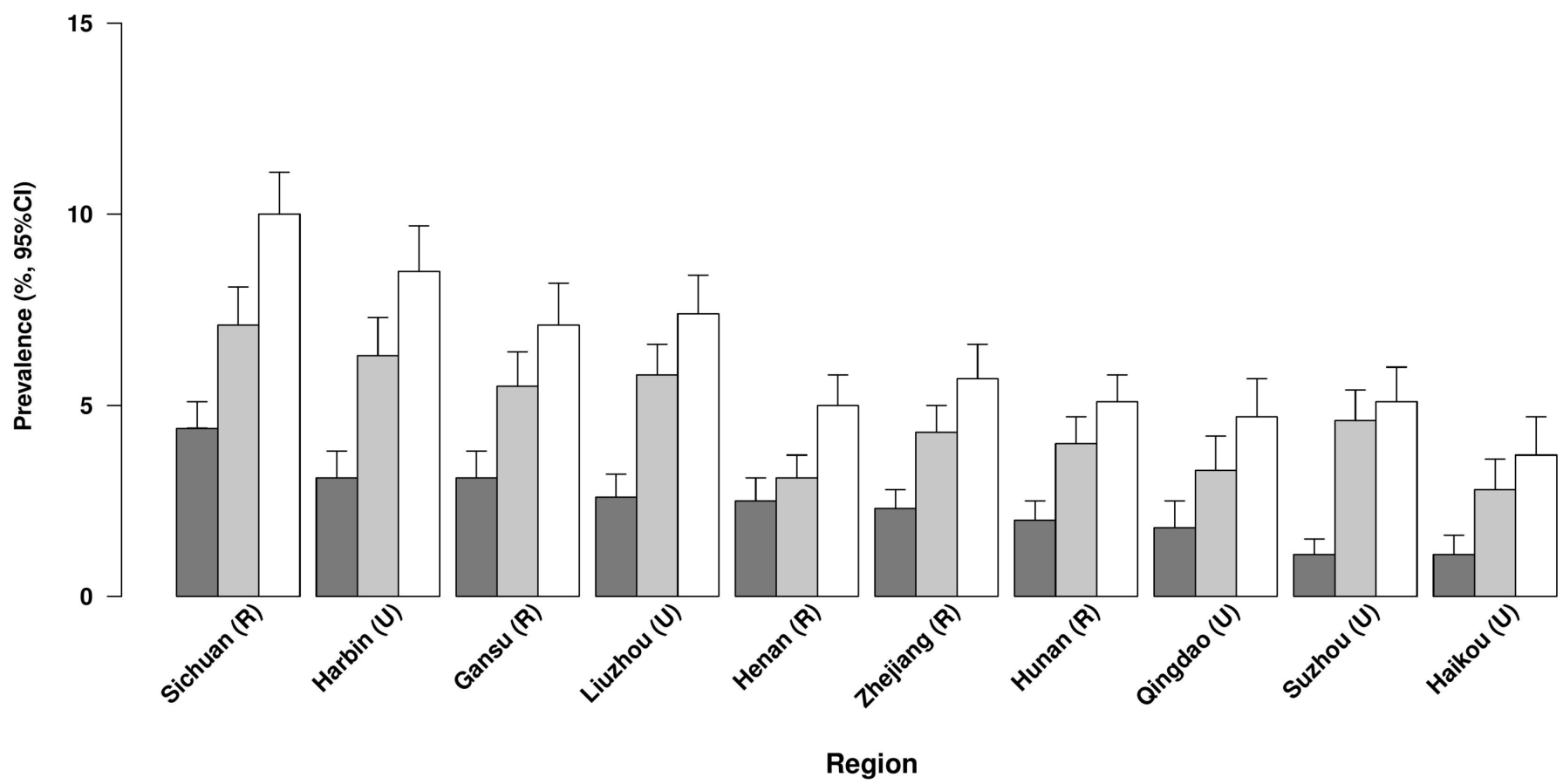

Figure 3 Prevalence of chronic obstructive pulmonary disease (COPD) defined by different criteria by region. The dark grey bar represents 'symptom-based COPD', grey bar represents 'doctor-diagnosed COPD' and the white bar represents 'symptom-based or doctor-diagnosed COPD' participants.

cases. Doctor-diagnosed COPD cases had better functional status despite having slightly lower levels of lung function indices than symptom-based COPD cases (table 2).

Over $80 \%$ of COPD cases reported that they were less than adequately or poorly informed about their condition and its treatment. The low levels of disease awareness were more pronounced in rural $(87 \%)$ than in urban areas $(73 \%)$ (see online supplementary table 2). Participants with doctor-diagnosed COPD were 1.5-times more likely to be aware of their condition compared with those with only symptom-based COPD (21\% vs $14 \%$; table 2 ).

\section{SENSITIVITY ANALYSES}

Among the 1586 COPD cases (by either definitions), $600(38 \%)$ were confirmed by spirometry using the lower limit of normal criteria (see online supplementary table 4). Those who had spirometric evidence of airflow obstruction in addition to having symptoms or a physician diagnosis were more likely to be older, males, and live in rural areas (see online supplementary table 5). As expected, they had a more severe condition, as noted by the higher proportions of CAT score $\geq 10$, self-reported severity and hospitalisation due to COPD (see online supplementary table 4), compared with all self-reported COPD cases (table 2). Nevertheless, there was no material difference in terms of the awareness and management of the disease between the spirometry-confirmed subset and the combined group of symptom-based or physician diagnosed individuals.

\section{DISCUSSION}

The present cross-sectional survey of 25011 Chinese adults conducted in the China Kadoorie Biobank cohort in 2013-2014 demonstrated substantial variation in COPD prevalence by age, sex and region. It also highlighted low levels of understanding about their diagnosis, unmet medical needs (indicated by symptoms, exacerbations and COPD-related health status) and very low use of appropriate medication for COPD in China. Indeed, use of medication was lowest in the rural regions where COPD was more common. These findings highlight the need for better recognition of COPD as a major healthcare problem in China and the need to improve the global management of this disease in the general population.

The prevalence of COPD was $6.3 \%$ in the present study and was similar to previous estimates reported for equivalent aged populations in China: $6.5 \%$ by the Regional COPD working group in $2003,{ }^{15} 2 \%-8 \%$ by the more recent Global Burden of Diseases Study ${ }^{16}$ and $8.2 \%$ for those $\geq 40$ years based on postbronchodilator spirometry from a large survey comprising seven rural and urban sites in China. ${ }^{6}$ Using the same definition as in the present study, the Continuing to Confront COPD International Survey (C2C),${ }^{17}$ a population-based survey estimated that the prevalence of COPD ranged from $6.5 \%$ to $11.8 \%$ in 12 countries among representative samples of adults aged $40+$ years, the samples being selected through telephone and face-to-face interviews from general population. While there were no data from China in $\mathrm{C} 2 \mathrm{C}$, the estimates for COPD were $7.0 \%$ in Japan and $8.2 \%$ in 
Table 2 Disease severity and management measures, by COPD subtypes

\begin{tabular}{|c|c|c|c|c|}
\hline Characteristics & Study population & $\begin{array}{l}\text { Symptom-based } \\
\text { COPD } \%(95 \% \mathrm{Cl})\end{array}$ & $\begin{array}{l}\text { Doctor-diagnosed } \\
\text { COPD } \%(95 \% \mathrm{Cl})\end{array}$ & $\begin{array}{l}\text { Symptom-based or } \\
\text { doctor-diagnosed } \\
\text { COPD } \%(95 \% \mathrm{Cl})\end{array}$ \\
\hline Participants & 1586 & 612 & 1193 & 1586 \\
\hline \multicolumn{5}{|l|}{ Lung function (mean $\pm S D$ ) } \\
\hline $\mathrm{FEV}_{1}(\mathrm{~L})$ & $1.8 \pm 0.1$ & $1.9 \pm 0.2$ & $1.7 \pm 0.1$ & $1.8 \pm 0.1$ \\
\hline FVC (L) & $2.6 \pm 0.2$ & $2.7 \pm 0.2$ & $2.5 \pm 0.2$ & $2.6 \pm 0.2$ \\
\hline $\mathrm{FEV}_{1} / \mathrm{FVC}(\%)$ & $67.1 \pm 2.5$ & $68.3 \pm 2.4$ & $65.6 \pm 2.6$ & $67.1 \pm 2.5$ \\
\hline \multicolumn{5}{|l|}{ CAT score } \\
\hline$<10$ & 882 & 50.1 (48.7 to 51.5$)$ & 54.2 (53.2 to 55.2 ) & 55.6 (54.8 to 56.5$)$ \\
\hline $10-20$ & 514 & 32.9 (31.6 to 34.2$)$ & 33.0 (32.0 to 33.9) & 32.4 (31.6 to 33.2) \\
\hline$>20$ & 190 & $17.0(15.9$ to 18.1$)$ & 12.8 (12.2 to 13.5$)$ & $12.0(11.4$ to 12.5$)$ \\
\hline \multicolumn{5}{|c|}{ Awareness of condition and treatment } \\
\hline Well informed & 295 & 13.8 (12.9 to 14.8$)$ & 20.7 (19.9 to 21.5$)$ & 18.6 (17.9 to 19.3$)$ \\
\hline $\begin{array}{l}\text { Inadequately/poorly } \\
\text { informed }\end{array}$ & 1114 & 72.2 (71.0 to 73.5$)$ & 69.8 (68.9 to 70.7$)$ & $70.2(69.5$ to 71.0$)$ \\
\hline Do not know & 177 & 13.9 (13.0 to 14.9$)$ & 9.4 (8.9 to 10.0$)$ & $11.2(10.6$ to 11.7$)$ \\
\hline \multicolumn{5}{|c|}{ Self-reported severity of chronic lung disease } \\
\hline Mild & 713 & 44.0 (42.6 to 45.3$)$ & 41.1 (40.1 to 42.1$)$ & 45.0 (44.1 to 45.8$)$ \\
\hline Moderate & 578 & 35.0 (33.7 to 36.4$)$ & 38.1 (37.1 to 39.1$)$ & 36.4 (35.6 to 37.3$)$ \\
\hline Severe & 295 & 21.0 (19.8 to 22.1$)$ & 20.8 (20.0 to 21.6$)$ & $18.6(17.9$ to 19.3$)$ \\
\hline \multicolumn{5}{|l|}{ Vaccination (last 12 months) } \\
\hline No & 1527 & 95.8 (95.3 to 96.4$)$ & 96.0 (95.6 to 96.4 ) & 96.3 (96.0 to 96.6$)$ \\
\hline Yes & 59 & 4.2 (3.6 to 4.7$)$ & 4.0 (3.6 to 4.4$)$ & 3.7 (3.4 to 4.0$)$ \\
\hline Influenza vaccination & 54 & 3.5 (3.0 to 4.0$)$ & 3.8 (3.4 to 4.2$)$ & 3.4 (3.1 to 3.7$)$ \\
\hline Pneumococcal vaccination & 14 & 1.4 (1.1 to 1.8$)$ & $0.9(0.7$ to 1.1$)$ & 0.9 (0.7 to 1.0$)$ \\
\hline \multicolumn{5}{|c|}{ Healthcare professional consultations (last 12 months) } \\
\hline No & 721 & 56.7 (55.3 to 58.1$)$ & 37.0 (36.0 to 37.9$)$ & 45.5 (44.6 to 46.3$)$ \\
\hline Yes & 865 & 43.3 (41.9 to 44.7$)$ & 63.0 (62.1 to 64.0$)$ & 54.5 (53.7 to 55.4$)$ \\
\hline General physician & 536 & 27.9 (26.6 to 29.1$)$ & 38.9 (38.0 to 39.9$)$ & 33.8 (33.0 to 34.6$)$ \\
\hline Respiratory specialist & 305 & $13.7(12.7$ to 14.7$)$ & $23.2(22.4$ to 24.1$)$ & $19.2(18.6$ to 19.9$)$ \\
\hline Cardiologist/heart specialist & 74 & 3.9 (3.3 to 4.4$)$ & 5.3 (4.9 to 5.8$)$ & 4.7 (4.3 to 5.0$)$ \\
\hline $\begin{array}{l}\text { Traditional Chinese } \\
\text { medicine doctor }\end{array}$ & 132 & $7.2(6.5$ to 7.9$)$ & 9.7 (9.1 to 10.3$)$ & 8.3 (7.9 to 8.8$)$ \\
\hline Other medical professional & 104 & 5.7 (5.0 to 6.3 ) & 7.3 (6.8 to 7.8$)$ & $6.6(6.1$ to 7.0$)$ \\
\hline \multicolumn{5}{|c|}{ Hospitalisation for COPD (last 12 months) } \\
\hline None & 1333 & 87.4 (86.5 to 88.3$)$ & 81.3 (80.5 to 82.1$)$ & 84.7 (84.1 to 85.4$)$ \\
\hline One & 182 & 8.6 (7.8 to 9.4$)$ & $14.2(13.5$ to 14.9$)$ & $11.6(11.0$ to 12.1$)$ \\
\hline$\geq$ Two & 58 & 3.9 (3.4 to 4.5$)$ & 4.5 (4.1 to 5.0$)$ & 3.7 (3.4 to 4.0$)$ \\
\hline \multicolumn{5}{|c|}{ Oxygen therapy at home (last 12 months) } \\
\hline No & 1523 & 96.7 (96.1 to 97.2 ) & 96.5 (96.1 to 96.9$)$ & 97.2 (96.9 to 97.5$)$ \\
\hline Yes & 44 & 3.3 (2.8 to 3.9$)$ & 3.5 (3.1 to 3.9$)$ & 2.8 (2.5 to 3.1$)$ \\
\hline \multicolumn{5}{|c|}{ Medication for COPD exacerbation (last 12 months) } \\
\hline No & 1072 & 71.8 (70.6 to 73.1$)$ & 62.4 (61.5 to 63.4$)$ & 67.6 (66.8 to 68.4$)$ \\
\hline Yes & 514 & 28.2 (26.9 to 29.4 ) & 37.6 (36.6 to 38.5 ) & 32.4 (31.6 to 33.2) \\
\hline Antibiotics & 483 & 26.5 (25.3 to 27.7$)$ & 35.5 (34.6 to 36.4 ) & 30.5 (29.7 to 31.2$)$ \\
\hline Oral steroids & 107 & 6.1 (5.4 to 6.8$)$ & $7.9(7.4$ to 8.4$)$ & 6.7 (6.3 to 7.2$)$ \\
\hline
\end{tabular}

Continued 
Table 2 Continued

\begin{tabular}{|c|c|c|c|c|}
\hline Characteristics & Study population & $\begin{array}{l}\text { Symptom-based } \\
\text { COPD \% }(95 \% \mathrm{CI})\end{array}$ & $\begin{array}{l}\text { Doctor-diagnosed } \\
\text { COPD } \%(95 \% \mathrm{CI})\end{array}$ & $\begin{array}{l}\text { Symptom-based or } \\
\text { doctor-diagnosed } \\
\text { COPD } \%(95 \% \mathrm{Cl})\end{array}$ \\
\hline Injectable steroids & 70 & $3.0(2.5$ to 3.4$)$ & $5.4(5.0$ to 5.9$)$ & 4.4 (4.1 to 4.8$)$ \\
\hline \multicolumn{5}{|c|}{ Number of COPD exacerbations after medication } \\
\hline None & 1185 & 77.4 (76.3 to 78.6$)$ & 70.4 (69.5 to 71.3$)$ & 74.7 (74.0 to 75.4$)$ \\
\hline One & 202 & 8.4 (7.6 to 9.2$)$ & 15.5 (14.8 to 16.2$)$ & $12.7(12.2$ to 13.3$)$ \\
\hline$\geq$ Two & 199 & 14.2 (13.2 to 15.2$)$ & 14.1 (13.4 to 14.8$)$ & 12.5 (12.0 to 13.1$)$ \\
\hline \multicolumn{5}{|c|}{ Prescribed medication (last 7 days) } \\
\hline No & 1447 & 90.8 (89.9 to 91.6$)$ & 89.8 (89.2 to 90.4$)$ & $91.2(90.7$ to 91.7$)$ \\
\hline Yes & 139 & $9.2(8.4$ to 10.1$)$ & 10.2 (9.6 to 10.8$)$ & 8.8 (8.3 to 9.3$)$ \\
\hline $\begin{array}{c}\text { Short-acting } \\
\text { bronchodilators }\end{array}$ & 25 & 2.1 (1.7 to 2.5$)$ & 2.0 (1.7 to 2.2$)$ & $1.6(1.4$ to 1.8$)$ \\
\hline Long-acting bronchodilators & 16 & 1.5 (1.2 to 1.9$)$ & $1.2(1.0$ to 1.4$)$ & $1.0(0.8$ to 1.2$)$ \\
\hline Oral bronchodilators & 19 & $1.0(0.7$ to 1.3$)$ & 1.4 (1.2 to 1.7$)$ & 1.2 (1.0 to 1.4$)$ \\
\hline Any inhalers & 11 & 0.5 (0.3 to 0.7$)$ & 0.8 (0.6 to 0.9$)$ & 0.7 (0.6 to 0.8$)$ \\
\hline $\begin{array}{l}\text { Traditional Chinese } \\
\text { medicine }\end{array}$ & 33 & 2.1 (1.6 to 2.5 ) & 2.6 (2.3 to 2.9 ) & 2.1 (1.8 to 2.3 ) \\
\hline Other treatments & 94 & 6.4 (5.7 to 7.1$)$ & 6.7 (6.2 to 7.2$)$ & 5.9 (5.5 to 6.3$)$ \\
\hline
\end{tabular}

*All data standardised for region, age group and gender as appropriate. Short-acting bronchodilators (short-acting beta ${ }_{2}$-agonist/short-acting muscarinic antagonist); long-acting bronchodilators (long-acting beta ${ }_{2}$-agonist/long-acting muscarinic antagonist).

CAT, COPD Assessment Test; COPD, chronic obstructive pulmonary disease; FEV ${ }_{1}$, forced expiratory volume in $1 \mathrm{~s}$; FVC, forced vital capacity.

South Korea. Few studies have investigated the reasons for variations in the pattern of COPD between or within countries. The present study demonstrated substantial region-specific differences (even within rural and urban areas), irrespective of smoking status and age groups. Access and utilisation of the healthcare services and, in the Chinese context, the capacity of healthcare professionals to diagnose COPD, could account for some of the observed differences across regions. ${ }^{18} 19$ However, further research in addition to the risk associated with tobacco exposure is needed to examine the role of environmental risk factors such as nutritional status, infection in early life, air pollution and occupational exposures for risk of COPD, and the quality of local healthcare provision which could further contribute to the regional variation observed.

In the present study, only $9 \%$ of the COPD cases (approximately 12\% in those who were also diagnosed
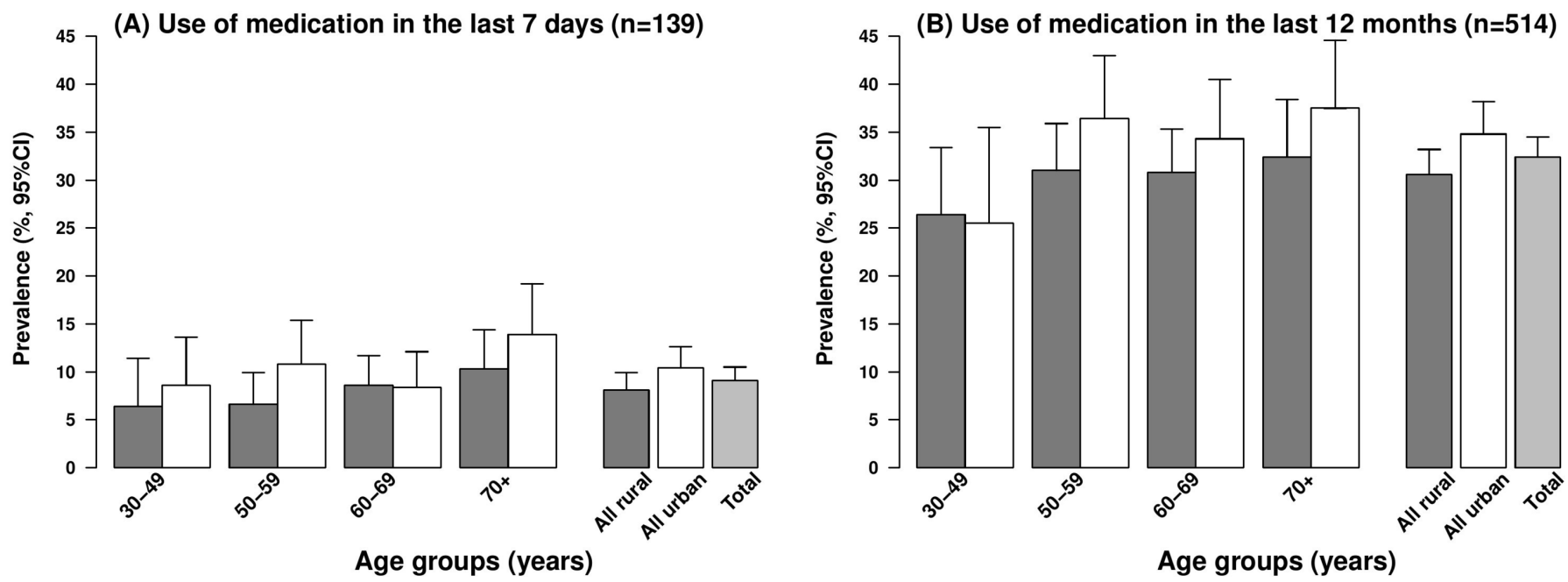

Figure 4 Use of medication among chronic obstructive pulmonary disease (COPD) cases by age and place of residence among 1586 COPD cases. The dark grey bar represents 'rural' and the white bar represents 'urban' participants. Medications include antibiotics or oral steroids or injectable steroids. 
Table 3 Use of COPD medication among COPD cases, in the last 7 days or the last 12 months prior to resurvey by gender, region, socioeconomic and smoking status

\begin{tabular}{|c|c|c|c|}
\hline Characteristics & Study population & $\begin{array}{l}\text { Use of medication* }(\%, \\
95 \% \mathrm{Cl}) \\
\text { Last } 7 \text { days }\end{array}$ & $\begin{array}{l}\text { Use of medicationt }(\% \text {, } \\
95 \% \mathrm{Cl}) \\
\text { Last } 12 \text { months }\end{array}$ \\
\hline Participants & 1586 & 139 & 514 \\
\hline \multicolumn{4}{|l|}{ Sex } \\
\hline Men & 772 & 9.6 (8.6 to 10.7$)$ & 30.0 (28.5 to 31.6$)$ \\
\hline Women & 814 & 8.0 (7.0 to 8.9$)$ & 34.6 (33.0 to 36.2 ) \\
\hline \multicolumn{4}{|l|}{ Area } \\
\hline Rural (R) & 911 & 7.8 (6.9 to 8.7 ) & 30.6 (29.1 to 32.1$)$ \\
\hline Urban (U) & 675 & 10.1 (9.0 to 11.2$)$ & 34.7 (32.9 to 36.5$)$ \\
\hline \multicolumn{4}{|l|}{ Regions $\ddagger$} \\
\hline Sichuan (R) & 265 & 7.0 (5.5 to 8.5$)$ & 10.3 (8.5 to 12.2$)$ \\
\hline Harbin (U) & 183 & 10.8 (8.6 to 13.0$)$ & 31.7 (28.3 to 35.1$)$ \\
\hline Gansu (R) & 173 & 10.4 (8.1 to 12.8$)$ & 65.7 (62.1 to 69.3 ) \\
\hline Liuzhou (U) & 216 & 10.5 (8.5 to 12.6$)$ & 26.2 (23.3 to 29.2 ) \\
\hline Henan $(\mathrm{R})$ & 147 & 0.6 (0.0 to 1.2$)$ & 14.9 (11.9 to 18.0$)$ \\
\hline Zhejiang (R) & 174 & 7.0 (5.0 to 8.9$)$ & 22.8 (19.7 to 25.9 ) \\
\hline Hunan (R) & 152 & 14.4 (11.4 to 17.3$)$ & 49.8 (45.7 to 54.0$)$ \\
\hline Qingdao (U) & 81 & 10.5 (7.2 to 13.8$)$ & 29.4 (24.4 to 34.4$)$ \\
\hline Suzhou (U) & 145 & $10.0(7.7$ to 12.4$)$ & 51.5 (47.4 to 55.5$)$ \\
\hline Haikou (U) & 50 & 7.5 (4.1 to 11.0$)$ & 40.9 (33.9 to 47.9$)$ \\
\hline \multicolumn{4}{|l|}{ Household income ( $¥)$} \\
\hline$<10000$ & 188 & 9.6 (7.7 to 11.4$)$ & 35.1 (32.7 to 37.5$)$ \\
\hline 10000-19999 & 208 & 9.1 (7.6 to 10.6$)$ & 36.2 (33.8 to 38.6) \\
\hline$\geq 20000$ & 1190 & 8.7 (8.2 to 9.3 ) & 31.9 (31.0 to 32.8$)$ \\
\hline \multicolumn{4}{|l|}{ Education } \\
\hline None & 326 & 8.5 (7.1 to 9.8$)$ & 31.1 (28.6 to 33.6$)$ \\
\hline Primary & 530 & 9.3 (8.3 to 10.3$)$ & 36.8 (35.4 to 38.3$)$ \\
\hline Secondary or tertiary & 730 & 8.2 (7.4 to 8.9$)$ & 28.3 (27.1 to 29.5 ) \\
\hline \multicolumn{4}{|l|}{ Smoking status } \\
\hline Never & 984 & 9.0 (8.2 to 9.7$)$ & 32.0 (30.9 to 33.0$)$ \\
\hline Ex-regular & 177 & 17.0 (14.6 to 19.4$)$ & 39.4 (36.5 to 42.3 ) \\
\hline Current regular & 425 & $8.3(6.6$ to 10.0$)$ & 27.1 (24.9 to 29.4 ) \\
\hline
\end{tabular}

*Medication questionnaire was completed only by those who had symptom-based COPD or history of doctor diagnosed COPD in the second resurveys; medication in last 7 days (short-acting bronchodilators, long-acting bronchodilators, oral bronchodilators, any inhaled medications, traditional Chinese medicine and any other treatments prescribed for COPD).

†Medication in last 12 months (antibiotics, oral corticosteroids, injectable corticosteroids). Standardised for region, age group and gender as appropriate.

$\ddagger$ The regions are ordered by COPD prevalence as in figure 3 .

COPD, chronic obstructive pulmonary disease.

by spirometry) reported receiving treatment for their disease, which was comparable to South Korea (11\%), but markedly lower than estimates for Russia $(21 \%)$ or for the UK $(72 \%) .{ }^{17}$ A higher rate of treatment among doctor-diagnosed and urban cases in the present study may reflect the fact that these COPD cases had more access to higher quality medical care.$^{20}$ Short-acting bronchodilators were the most frequently used medication in the present study in contrast to the international recommendations that advocate the use of long-acting bronchodilators (either beta $_{2}$-agonists or antimuscarinics) to reduce the symptoms and the frequency of exacerbations of COPD..$^{21-23}$ As COPD-related symptoms, assessed by either the CAT or the Modified British Medical Research Council Questionnaire, should guide drug treatment according to Global Initiative for Chronic Obstructive Lung Disease (GOLD) guidelines, at least $44 \%$ of the COPD cases with a CAT scores $\geq 10$ would be eligible to receive long-acting 
bronchodilators in the present study. ${ }^{23}$ While it is well established that influenza immunisation is a highly effective measure to reduce rates of exacerbations and hospitalisations due to COPD, ${ }^{24}{ }^{25}$ the reported use of vaccination was low, perhaps reflecting absence of a routine influenza vaccination programme in China. ${ }^{26}$

Exacerbations of COPD were reported more frequently in urban than in rural areas. This may reflect a more crowded living environment, higher levels of ambient air pollution or a greater awareness of the link between pollution and exacerbation of COPD in the cities. ${ }^{27-30}$ Alternatively, cases living in rural regions may have been less likely to seek medical advice for the alleviation of symptoms due to poor access to healthcare or due to financial constraints. ${ }^{31}{ }^{32}$ The annual hospitalisation rate $(15 \%)$ for COPD observed in this survey was comparable to the global average $(15 \%)$ reported from 12 countries by Landis et al. ${ }^{17}$ Despite the lower rate of exacerbations of COPD reported in rural areas in China, hospitalisation rates indicating severe exacerbations were similar in rural and urban areas. Exacerbation seemed to be a factor associated with receiving some form of medical treatment as $78 \%$ of those with an exacerbation during the previous 12 months reported receiving treatment for their COPD, consistent with standard recommendations. ${ }^{23}$

Participants with COPD had poor awareness of their diagnosis, and awareness was higher for the doctor-diagnosed than for symptom-based COPD cases. Cases living in urban areas were better informed than their rural counterparts, perhaps due to better socio-educational status or better access to healthcare services. In contrast, in rural areas the disease was more frequently described as severe or very severe, consistent with previous reports elsewhere. ${ }^{33-35}$ Variation by case definition, rural/urban or smoking status was not observed in the CAT score measuring COPD-related health status, although there was variation in CAT across regions. Similarly limited utility of the CAT in the characterisation of COPD has also been previously reported in China. ${ }^{18}$

The present study has several strengths, including the large number of COPD cases, the variation in geographic region and levels of socioeconomic circumstances included in the study population and clinical measures such as spirometry testing along with self-reported information. As the survey was conducted in 2013-2014, the findings are likely to reflect the current management of COPD in China. The present study also has a number of limitations. Although the response rate was reasonable for the second resurvey that is the basis of the current manuscript, the baseline response rate was only about $30 \%$, so results may not be representative of the general population. The COPD cases were defined through self-reported questionnaires and prebronchodilator spirometry (postbronchodilator is the current gold standard for diagnosis of COPD) ${ }^{23}$ Nevertheless, the estimates of COPD prevalence in the present study are consistent with previous studies in China ${ }^{61516}$ and are comparable in magnitude with those reported in other countries using a similar approach. However, we cannot completely exclude the possibility that some of the cases with reported COPD may also have asthma (asthma-COPD overlap syndrome). ${ }^{17}$ We would also argue that a symptom-based and self-reported definition is better suited for the aim of this study, which focused on the management and awareness of COPD as spirometry is not widely used in low-income and middle-income countries. Indeed, even when restricting to cases that were confirmed by spirometry, which tended to be more severe, the overall message that COPD has not been adequately managed was unaltered. Likewise, we relied on self-reported healthcare and medication use, which might have underestimated the true prevalence. Nevertheless, the study highlights the need for combined use of questionnaires and spirometry for diagnosis of COPD in future population studies if feasible as self-reported questionnaires alone have a limited sensitivity and specificity for diagnosis. In this largely descriptive analysis, we were unable to identify the sources which explained the variation within and between regions in the prevalence of COPD; the lack of strong associations may reflect lack of specificity in the COPD phenotypes measured, or differences in clinical practice or differences in access to healthcare in China ${ }^{18}$ or to some unmeasured factors responsible for the development of and susceptibility to COPD. Further longitudinal studies are needed to address these questions.

\section{CONCLUSIONS}

In summary, the burden of COPD among Chinese adults is high, particularly among those living in rural areas and complicated by a suboptimal management of the disease. The infrequent use of the healthcare system and the low levels of disease awareness reported by those with COPD, therefore, represent a serious deficit in public health services, healthcare education and patient engagement in China which would benefit from additional focused resources.

Acknowledgements The chief acknowledgment is to the participants, the project staff and the China National Center for Disease Control and Prevention (CDC) and its regional offices for assisting with the fieldwork. The authors would like to thank Judith Mackay in Hong Kong; Yu Wang, Gonghuan Yang, Zhengfu Qiang, Lin Feng, Maigeng Zhou, Wenhua Zhao and Yan Zhang in China CDC; Lingzhi Kong, Xiucheng Yu and Kun Li in the Chinese Ministry of Health; and Sarah Clark, Martin Radley, Mike Hill, Hongchao Pan in the CTSU, Oxford, for assisting with the design, planning, organization, and conduct of the study . The British Heart Foundation, UK Medical Research Council and Cancer Research provide core funding to the Clinical Trial Service Unit and Epidemiological Studies Unit at Oxford University for the project. Support for the present respiratory study was partly provided by GlaxoSmithKline (WEUKBRE5848).

Collaborators Members of the China Kadoorie Biobank collaborative group: International Steering Committee: Junshi Chen, Zhengming Chen (PI), Robert Clarke, Rory Collins, Yu Guo, Liming Li (PI), Jun Lv, Richard Peto, Robin Walters. International Co-ordinating Centre, Oxford: Daniel Avery, Ruth Boxall, Derrick

Bennett, Yumei Chang, Yiping Chen, Zhengming Chen, Robert Clarke, Huaidong Du, 
Simon Gilbert, Alex Hacker, Michael Holmes, Christiana Kartsonaki, Rene Kerosi, Om P Kurmi, Garry Lancaster, Kuang Lin, John McDonnell, Iona Millwood, Qunhua Nie, Jayakrishnan Radhakrishnan, Paul Ryder, Sam Sansome, Dan Schmidt, Rajani Sohoni, Becky Stevens, lain Turnbull, Robin Walters, Jenny Wang, Lin Wang, Neil Wright, Ling Yang, Xiaoming Yang. National Co-ordinating Centre, Beijing: Zheng Bian, Yu Guo, Xiao Han, Can Hou, Jun Lv, Pei Pei, Chao Liu, Biao Jing, Yunlong Tan, Canqing Yu. 10 Regional Co-ordinating Centres: Qingdao Qingdao CDC: Zengchang Pang, Ruqin Gao, Shanpeng Li, Shaojie Wang, Yongmei Liu, Ranran Du, Yajing Zang Liang Cheng, Xiaocao Tian, Hua Zhang, Yaoming Zhai, Feng Ning, Xiaohui Sun, Feifei Li. Licang CDC: Silu Lv, Junzheng Wang, Wei Hou. Heilongjiang Provincial CDC: Mingyuan Zeng, Ge Jiang, Xue Zhou. Nangang CDC: Liqiu Yang, Hui He, Bo Yu, Yanjie Li, Qinai Xu,Quan Kang, Ziyan Guo. Hainan Provincial CDC: Dan Wang, Ximin Hu, Hongmei Wang, Jinyan Chen, Yan Fu, Zhenwang Fu, Xiaohuan Wang. Meilan CDC: Min Weng, Zhendong Guo, Shukuan Wu,Yilei Li, Huimei Li, Zhifang Fu . Jiangsu Provincial CDC: Ming Wu, Yonglin Zhou, Jinyi Zhou, Ran Tao, Jie Yang, Jian Su. Suzhou CDC:Fang liu, Jun Zhang, Yihe Hu, Yan Lu, Liangcai Ma, Aiyu Tang, Shuo Zhang, Jianrong Jin, Jingchao Liu. Guangxi Provincial CDC: Zhenzhu Tang, Naying Chen, Ying Huang. Liuzhou CDC: Mingqiang Li, Jinhuai Meng, Rong Pan, Qilian Jiang, Jian Lan, Yun Liu, Liuping Wei, Liyuan Zhou, Ningyu Chen Ping Wang, Fanwen Meng, Yulu Qin, Sisi Wang. Sichuan Provincial CDC: Xianping Wu, Ningmei Zhang, Xiaofang Chen,Weiwei Zhou. Pengzhou CDC: Guojin Luo, Jianguo Li, Xiaofang Chen, Xunfu Zhong, Jiaqiu Liu, Qiang Sun. Gansu Provincial CDC: Pengfei Ge, Xiaolan Ren, Caixia Dong. Maiji CDC: Hui Zhang, Enke Mao, Xiaoping Wang, Tao Wang, Xi zhang. Henan Provincial CDC: Ding Zhang, Gang Zhou, Shixian Feng, Liang Chang, Lei Fan. Huixian CDC: Yulian Gao, Tianyou He, Huarong Sun, Pan He, Chen Hu, Xukui Zhang, Huifang Wu, Pan He. Zhejiang Provincial CDC: Min Yu, Ruying Hu, Hao Wang. Tongxiang CDC: Yijian Qian, Chunmei Wang, Kaixu Xie, Lingli Chen, Yidan Zhang, Dongxia Pan, Qijun Gu. Hunan Provincial CDC: Yuelong Huang, Biyun Chen, Li Yin, Huilin Liu, Zhongxi Fu, Qiaohua Xu. Liuyang CDC: Xin Xu, Hao Zhang, Huajun Long, Xianzhi Li, Libo Zhang, Zhe Qiu.

Contributors All authors made substantial contributions to this study. OPK was involved in the conception and design of the study, acquisition and analysis of the data, in writing the article and in its revision prior to submission. KD was involved in the design of the study, analysis plan and in its revision prior to submission. $\mathrm{KBHL}, \mathrm{JV}, \mathrm{DB}$ and $\mathrm{RC}$ were involved in the analysis plan, in writing the article and in its revision prior to submission. JW was involved in the analysis plan, carrying out the statistical analysis and in the revision of this article prior to submission $Y G, Z B$, $H D$, LL were involved in the design of the study, acquisition of the data and in the revision of this article prior to submission. ZC was involved in the conception and design of the study, its revision prior to submission and overall supervision of the project.

Funding The CKB baseline survey and the first resurvey were supported by the Kadoorie Charitable Foundation in Hong Kong. The long-term follow-up has been supported by the UK Wellcome Trust (202922/Z/16/Z, 104085/Z/14/Z, $088158 / \mathrm{Z} / 09 / \mathrm{Z}$ ) and grants from the National Natural Science Foundation of China $(81390540,81390541,81390544)$ and from the National Key Research and Development Program of China (2016YFC0900500, 2016YFC0900501, 2016YFC0900504, 2016YFC1303904).

Competing interests $\mathrm{KD}$ is a full-time employee of and owns shares in GlaxoSmithKline.

\section{Patient consent Obtained.}

Ethics approval International (Oxford Tropical Research Ethics Committee), national (Chinese Academy of Medical Sciences) and local (from 10 Centers for Disease Control of each region).

Provenance and peer review Not commissioned; externally peer reviewed.

Data sharing statement Please visit http://www.ckbiobank.org/site/Data+Access for data access policy.

Open Access This is an Open Access article distributed in accordance with the terms of the Creative Commons Attribution (CC BY 4.0) license, which permits others to distribute, remix, adapt and build upon this work, for commercial use, provided the original work is properly cited. See: http://creativecommons.org/ licenses/by/4.0/

C) Article author(s) (or their employer(s) unless otherwise stated in the text of the article) 2018. All rights reserved. No commercial use is permitted unless otherwise expressly granted.

\section{REFERENCES}

1. Lozano R, Naghavi M, Foreman K, et al. Global and regional mortality from 235 causes of death for 20 age groups in 1990 and 2010: a systematic analysis for the Global Burden of Disease Study 2010. Lancet 2012;380:2095-128.
2. Burney PG, Patel J, Newson R, et al. Global and regional trends in COPD mortality, 1990-2010. Eur Respir J 2015;45:1239-47.

3. Yang $G$, Wang $Y$, Zeng $Y$, et al. Rapid health transition in China, 1990-2010: findings from the Global Burden of Disease Study 2010. Lancet 2013;381:1987-2015.

4. Chen Z, Peto R, Zhou M, et al. Contrasting male and female trends in tobacco-attributed mortality in China: evidence from successive nationwide prospective cohort studies. Lancet 2015;386:1447-56.

5. Kurmi OP, Li L, Smith M, et al. Regional variations in the prevalence and misdiagnosis of air flow obstruction in China: baseline results from a prospective cohort of the China Kadoorie Biobank (CKB). BMJ Open Respir Res 2014;1:e000025

6. Zhong N, Wang C, Yao W, et al. Prevalence of chronic obstructive pulmonary disease in China: a large, population-based survey. Am J Respir Crit Care Med 2007;176:753-60.

7. Chen Z, Lee L, Chen J, et al. Cohort profile: the Kadoorie Study of Chronic Disease in China (KSCDC). Int J Epidemiol 2005;34:1243-9.

8. Chen Z, Chen J, Collins R, et al. China Kadoorie Biobank of 0.5 million people: survey methods, baseline characteristics and longterm follow-up. Int J Epidemiol 2011;40:1652-66.

9. Definitions E. Pathophysiology, Diagnosis, and Staging. Am J Resp Crit Care 1995;152:S78-S83.

10. Jones PW, Harding G, Berry P, et al. Development and first validation of the COPD Assessment Test. Eur Respir J 2009;34:648-54.

11. Davis KJ, Landis SH, Oh YM, Ym O, et al. Continuing to Confront COPD International Physician Survey: physician knowledge and application of COPD management guidelines in 12 countries. Int J Chron Obstruct Pulmon Dis 2015;10:39-55.

12. Cooper BG. An update on contraindications for lung function testing Thorax 2011;66.

13. Pellegrino R, Viegi G, Brusasco V, et al. Interpretative strategies for lung function tests. Eur Respir J 2005;26:948-68.

14. Quanjer PH, Stanojevic S, Cole TJ, et al. Multi-ethnic reference values for spirometry for the 3-95-yr age range: the global lung function 2012 equations. Eur Respir J 2012;40:1324-43.

15. Regional COPD Working Group. COPD prevalence in 12 Asia-Pacific countries and regions: projections based on the COPD prevalence estimation model. Respirology 2003;8:192-8.

16. Lopez AD, Shibuya K, Rao C, et al. Chronic obstructive pulmonary disease: current burden and future projections. Eur Respir $J$ 2006;27:397-412.

17. Landis $\mathrm{SH}$, Muellerova H, Mannino DM, et al. Continuing to Confront COPD International Patient Survey: methods, COPD prevalence, and disease burden in 2012-2013. Int J Chron Obstruct Pulmon Dis 2014;9:597-611.

18. Shen N, He B. Is the new GOLD classification applicable in China? Lancet Glob Health 2013;1:e247-8.

19. Kurmi OP, Li L, Wang J, et al. COPD and its association with smoking in the Mainland China: a cross-sectional analysis of 0.5 million men and women from ten diverse areas. Int $J$ Chron Obstruct Pulmon Dis 2015;10:655-65.

20. Price D, West D, Brusselle G, et al. Management of COPD in the UK primary-care setting: an analysis of real-life prescribing patterns. Int J Chron Obstruct Pulmon Dis 2014;9:889-904.

21. Miravitlles $M$, Vogelmeier $C$, Roche $N$, et al. A review of national guidelines for management of COPD in Europe. Eur Respir $J$ 2016;47:625-37.

22. Cazzola M, Page C. Long-acting bronchodilators in COPD: where are we now and where are we going? Breathe 2014;10:110-20.

23. Global Initiative for Chronic Obstructive Lung Disease (GOLD). Global strategy for diagnosis, management, and prevention of COPD 2015. http://www.goldcopd.org/guidelines-global-strategy-fordiagnosis-management.html (accessed 25 Jun 2015).

24. Lall D, Cason E, Pasquel FJ, et al. Effectiveness of Influenza Vaccination for Individuals with Chronic Obstructive Pulmonary Disease (COPD) in Low- and Middle-Income Countries. COPD 2016;13:93-9.

25. Garrastazu R, García-Rivero JL, Ruiz M, et al. Prevalence of Influenza Vaccination in Chronic Obstructive Pulmonary Disease Patients and Impact on the Risk of Severe Exacerbations. Arch Bronconeumol 2016;52:88-95.

26. $\mathrm{Yu} \mathrm{H}$, Alonso WJ, Feng $\mathrm{L}$, et al. Characterization of regional influenza seasonality patterns in China and implications for vaccination strategies: spatio-temporal modeling of surveillance data. PLoS Med 2013;10:e1001552

27. Ni L, Chuang CC, Zuo L. Fine particulate matter in acute exacerbation of COPD. Front Physiol 2015;6:294.

28. Romieu I, Gouveia N, Cifuentes LA, et al. Multicity study of air pollution and mortality in Latin America (the ESCALA study). Res Rep Health Eff Inst 2012;5:86. 
29. Ling SH, van Eeden SF. Particulate matter air pollution exposure: role in the development and exacerbation of chronic obstructive pulmonary disease. Int J Chron Obstruct Pulmon Dis 2009;4:233-43.

30. Arbex MA, de Souza Conceição GM, Cendon SP, et al. Urban air pollution and chronic obstructive pulmonary disease-related emergency department visits. J Epidemiol Community Health 2009;63:777-83.

31. Goodridge D, Lawson J, Rennie D, et al. Rural/urban differences in health care utilization and place of death for persons with respiratory illness in the last year of life. Rural Remote Health 2010;10:1349.

32. Liu Z, Albanese E, Li S, et al. Chronic disease prevalence and care among the elderly in urban and rural Beijing, China - a 10/66
Dementia Research Group cross-sectional survey. BMC Public Health 2009;9:394-94.

33. Wong SS, Abdullah N, Abdullah A, et al. Unmet needs of patients with chronic obstructive pulmonary disease (COPD): a qualitative study on patients and doctors. BMC Fam Pract 2014;15:67.

34. Hernandez P, Balter M, Bourbeau J, et al. Living with chronic obstructive pulmonary disease: a survey of patients' knowledge and attitudes. Respir Med 2009;103:1004-12.

35. Lou P, Zhu Y, Chen P, et al. Vulnerability, beliefs, treatments and economic burden of chronic obstructive pulmonary disease in rural areas in China: a cross-sectional study. BMC Public Health 2012;12:287-87. 